\title{
Respiratory diphtheria in an asylum seeker from Afghanistan arriving to Finland via Sweden, December 2015
}

J Sane ${ }^{1}$, T Sorvari ${ }^{1}$, M Widerström* ${ }^{2}$, H Kauma ${ }^{3}$, U Kaukoniemi ${ }^{4}$, E Tarkka ${ }^{5}$, T Puumalainen ${ }^{6}$, M Kuusi ${ }^{1}$, M Salminen ${ }^{1}, 0$ Lyytikäinen ${ }^{1}$

1. Department of Infectious Diseases, Infectious Disease Control Unit, National Institute for Health and Welfare, Helsinki, Finland

2. Department of Communicable Disease Control and Prevention, Stockholm County Council, Stockholm, Sweden

3. Department of Internal Medicine, Oulu University Hospital, Oulu, Finland

4. Department of Infectious Diseases, Länsi-Pohja Central Hospital, Finland

5. Helsinki University Central Hospital, Hospital District of Helsinki and Uusimaa, Laboratory Services, HUSLAB, Finland

6. Department of Health Protection, Vaccination Programme Unit, National Institute for Health and Welfare, Helsinki, Finland

Correspondence: Jussi Sane (jussi.sane@thl.fi)

Sane J, Sorvari T, Wideström M, Kauma H, Kaukoniemi U, Tarkka E, Puumalainen T, Kuusi M, Salminen M, Lyytikäinen O. Respiratory diphtheria in an asylum

seeker from Afghanistan arriving to Finland via Sweden, December 2015. Euro Surveill. 2016;21(2):pii=30105. DOI: http://dx.doi.org/10.2807/1560-7917.

ES.2016.21.2.30105

Article submitted on 15 December 2015 / accepted on 13 January 2016 / published on 14 January 2016

In December 2015, an asylum seeker originating from Afghanistan was diagnosed with respiratory diphtheria in Finland. He arrived in Finland from Sweden where he had already been clinically suspected and tested for diphtheria. Corynebacterium diphtheriae was confirmed in Sweden and shown to be genotypically and phenotypically toxigenic. The event highlights the importance of early case detection, rapid communication within the country and internationally as well as preparedness plans of diphtheria antitoxin availability.

An asylum seeker from Afghanistan was diagnosed with respiratory diphtheria in Finland in December 2015. He arrived in Finland from Sweden where he was already symptomatic with fever and respiratory symptoms and had been suspected for diphtheria. In this report we present details of this case investigation.

\section{Case description}

On 26 November 2015, an adolescent male originating from Afghanistan arrived in a transit accommodation centre designated for asylum seekers in Stockholm, Sweden. Prior to this, he had travelled from Afghanistan to Pakistan, then through Iran, Turkey, Greece, Serbia and Germany to Sweden (timeline of events presented in the Figure).

The case showed some symptoms (pharyngitis and fever) while in Germany (further details on duration of stay and locations not known) and upon arrival in Stockholm, he presented with intense pharyngitis, fever and general malaise and was rapidly escorted by the transit centre staff to a nearby emergency department where he stayed overnight. The preliminary diagnosis was tonsillitis positive for group A streptococcus (QuickVue Dipstick Strep A Test, TK Diagnostic, Oxford, United Kingdom). Oral penicillin was prescribed as treatment. As diphtheria was among the differential diagnoses, the attending physician also requested a specimen for throat culture. According to the patient, he had never received any vaccinations. The patient was discharged from the hospital and returned to the asylum accommodation centre. On the following day, 27 November, he left the centre in Stockholm with two other asylum seekers and did not take the prescribed antibiotics along. Their travel destination was not clear at the time but according to the anecdotal evidence, Switzerland, Germany and Finland were mentioned.

On 29 November the asylum seeker arrived in Finland crossing the border in Northern Finland. He had travelled from Stockholm to the north of Sweden by an overnight train from where he moved on to Finland by bus.

When arriving in Finland, he was still unwell and was immediately transferred to a regional central hospital where he was put in isolation as a precautionary measure. Streptococcal tonsillitis and mononucleosis were initially suspected. Subsequently diphtheria was also considered and specimen for PCR amplification (toxin gene) was taken on 30 November and for Corynebacterium diphtheria culture on 1 December. On 2 December, the patient was transferred to the nearest university hospital for further treatment. 


\section{FIGURE 1}

Timeline of events for the diphtheria case, in an asylum seeker from Afghanistan arriving to Finland via Sweden, November to December 2015

$\longrightarrow$ Dates and events in Sweden

$\longrightarrow$ Dates and events in Finland

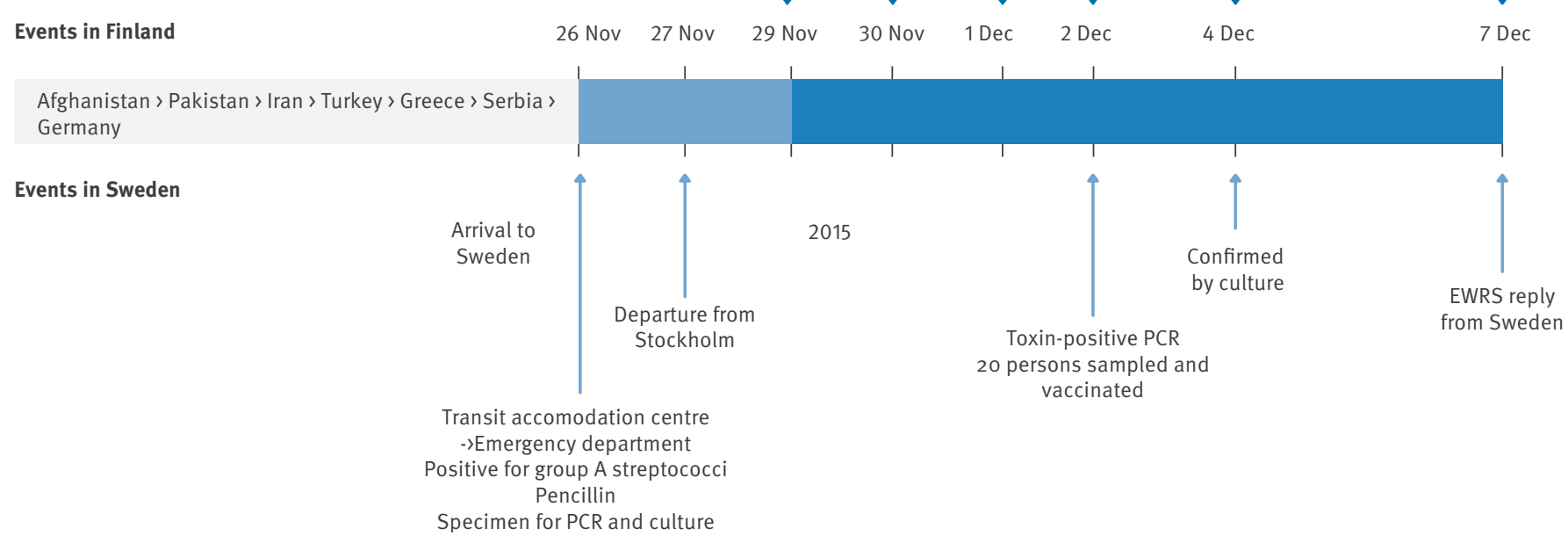

EWRS: Early Warning Response System.

While in hospital, the patient presented with malaise, sore throat and low-grade fever. Membranes in tonsils and soft palate were noticed. Carditis was evident with chest pain, ST-T wave changes in electrocardiograph and considerably elevated cardiac troponin I concentration $(70 \mu \mathrm{g} / \mathrm{l}$, norm: $\leq 0.04 \mu \mathrm{g} / \mathrm{l})$. Treatment with intravenous cefuroxime and oral roxithromycin was introduced on 29 November and 20,000 IU diphtheria antitoxin (DAT, Institute of Immunology, Croatia) was given on 2 and 4 December. On 11 December, the patient was assessed to be cured and discharged.

\section{Laboratory findings in Sweden and Finland} On 4 December, the National Institute for Health and Welfare in Finland was alerted by a clinical laboratory the throat swab was positive for $C$. diphtheria toxin gene in the PCR. Isolation of the bacteria was attempted but was not successful. Prior penicillin therapy in Sweden, although incomplete, may have impeded a positive culture in this case.

In Sweden, on 1 December, the local county medical officer in Stockholm was alerted by the local clinical microbiological laboratory of a suspicion of diphtheria based on a positive Maldi-TOF finding of $C$. diphtheriae. The Public Health Agency of Sweden received the strain on the same day and informed on 2 December the local county medical officer of the presence of the diphtheria toxin gene (as analysed by PCR) in the isolate. The strain was Elek-positive confirming suspected toxin-production on 3 December and subsequently biochemical species determination confirmed the isolate to be $C$. diphtheriae and sub species non-gravis [personal communication, Karin Tegmark-Wisell, Public Health Agency of Sweden, December 2015].

On 7 December, Finland posted a message in the European Early Warning and Response System (EWRS) describing the event. Sweden replied the same day disclosing the details about patient's travel itinerary, symptoms and laboratory findings before his arrival in Finland.

\section{Specific and general public health measures in Sweden and Finland}

The local public health authorities in Stockholm visited the transit accommodation centre on 3 and 4 December after the suspicion of diphtheria was notified (toxin positivity by P(R). The team examined the premises, obtained throat swabs and vaccinated nearly 20 adolescents (mostly from Afghanistan) out of the ca 30 persons who could have resided in the same room with the case patient. The other persons had already left the centre. None of the surveyed persons were ill and all cultures were negative.

In Finland, the patient was wearing a mask on the bus upon arrival (given by the police at the border) and was rapidly transferred to an isolation room after he crossed the border. Thus, the number of potentially exposed persons was limited. The contact details and 
whereabouts of two travel companions from Stockholm were investigated but they could not be contacted.

The National Institute for Health and Welfare in Finland has recommended free of charge vaccination against diphtheria, tetanus (dT), polio (IPV), measles-mumpsrubella (MMR) and influenza as a priority for all adult asylum seekers and refugees with an unknown or incomplete history of vaccination, or lack of protection gained through previous MMR infections. The children are offered the normal national immunisation programme, modified and speeded up as appropriate. As an occupational health measure, the vaccination status of all personnel working at the accommodation centres is checked and dT, MMR, influenza and hepatitis A vaccines are offered when necessary.

\section{Background}

Diphtheria is an acute bacterial disease primarily involving the mucous membrane of the upper respiratory tract, skin or seldom other mucous membranes $[1,2]$. The infection spreads from person to person through respiratory droplets, direct contact with respiratory secretions or from skin lesions. The incubation period is usually two to five days, sometimes up to 10 days. The toxin-mediated disease caused by $C$. diphtheria can be prevented by vaccination, which protects against the effects of exotoxin produced by the bacteria [3].

This patient is the first diphtheria case diagnosed in Finland since 2001. Diphtheria is still endemic or epidemic in many regions of the world, including origin countries for current asylum seekers in Europe $[3,4]$.

\section{Discussion}

Except for the present case, no cases of respiratory diphtheria were reported among asylum seekers and refugees since the current European refugee crisis started in 2015. Cases of cutaneous diphtheria were recently reported in refugees from Denmark, Germany and Sweden [5]. These events highlight the possibility of diphtheria among these vulnerable groups and underpins the need of national guidance regarding laboratory capacity for confirming diphtheria infections, raising awareness among clinicians, and early recognition and prompt implementation of prevention and control measures by the public health authorities. Since the exact timeline of the patient's travel itinerary was unclear, the source of infection and whether it was acquired within or outside the European Union (EU) remains unknown.

Our case further highlights that refugees arriving in the EU are likely not to be fully vaccinated against an array of vaccine-preventable diseases. They are consequently at greater risk of communicable diseases such as diphtheria or measles. In Finland, the public health authorities recommend prompt vaccination of the newly arriving asylum seekers and refugees newcomers, ideally within two weeks of arrival to the country. Due to logistics and resource constrains this target has not yet been achieved in most of the newly opened accommodation centres. As also shown in our case, another challenge to the immunisation activities is the mobility of refugees, not only cross-border but also within the country. The accommodation centre may change several times during the asylum process, which addresses the need for reliable online registry with immunisation data available for all healthcare staff providing services for the refugee population.

In general, refugees do not pose a threat to general population in Europe with respect to communicable diseases and they are themselves most vulnerable [6]. Since 1995, the vaccination coverage of Finnish children against diphtheria has been $94 \%$ to $99 \%$ [7]. However, there are no official estimates of the decennial dT booster vaccination coverage among the adults and elderly persons. It is likely that at least a part of the adult population will be at risk for diphtheria and other vaccine preventable diseases. This emphasises the need for a vaccination policy that guarantees lifelong protection against significant infectious diseases threats.

The patient was treated with DAT which was available at the adjacent university hospital. The batch of DAT used had expired in March 2014 but was previously evaluated by the Finnish Medical Agency to be still safe and efficacious for use in emergency situation (personal communication, Pertti Sormunen, Director of Pharmaceutical Wholesale, National Institute for Health and Welfare, December 2015). The potency of the DAT was tested according to the European Pharmacopoeia monograph for Diphtheria Antitoxin (intradermal challenge in guinea pigs) by an authorised laboratory in February 2014. The diphtheria potency was still more than three times over the minimum level of $1,000 \mathrm{IU} /$ $\mathrm{ml}$. No abnormal toxicity was detected.

The rapid administration of DAT is crucial for a successful treatment effect [3]. However, a large number of EU Member States do not have stockpiles and many countries have difficulties in having rapid access to DAT, a problem highlighted in a recent case of diphtheria in Spain [8]. Many countries ceased manufacturing DAT following the significant decline in incidence of the diphtheria after the mass vaccination campaigns in Europe [4]. The lack of DAT availability in the EU is worrying and needs urgent attention in the light of this event. Possibilities for joint procurement of DAT in the EU/European Economic Area (EEA) should be assessed as suggested by the European Centre for Disease Prevention and Control (ECDC) [8].

Prompt communication between clinicians, microbiology laboratories and public health authorities is crucial in the effective public health response. The patient was found PCR-positive for toxin gene on 2 December in Sweden (but yet not confirmed by culture) two days before the clinical laboratory in Finland alerted 
the national public health institute about the positive PCR finding for the toxin gene. Swedish authorities were not fully aware of the travel route and thus not able to directly alert Finnish authorities before arrival in Finland. However, due to the apparent problems in DAT availability in the EU and the importance of rapid public health measures for treating and controlling diphtheria, we propose that any suspected or probable case among highly mobile migrant populations, is communicated through the EWRS as early as possible.

\section{${ }^{*}$ Authors' correction}

The name of Micael Widerström was corrected upon request of the authors on 1 February 2016.

\section{Acknowledgements}

Otto Helve (National Institute for Health and Welfare, Finland) is thanked for assistance in the investigation. Karin Tegmark-Wisell and Eva Morfeldt are thanked for microbiological analyses at the Public Health Agency of Sweden.

\section{Conflict of interest}

None declared.

\section{Authors' contributions}

JS was the officer on duty during the event, JS designed the study, coordinated the data collection and wrote the manuscript. TS contributed to the data collection and drafted the timeline figure. MW led the Swedish response and data collection. HK and UK were the treating physicians in Finland and provided the clinical details of the case. ET provided laboratory input, TP reviewed and the manuscript. MK reviewed the manuscript. MS reviewed the manuscript. OL designed the study, coordinated data collection and wrote the manuscript.

\section{References}

1. Heymann DL, editor. Control of Communicable Diseases Manual. 19th ed. Washington, D.C.: American Public Health Association; 2008.

2. Mandel G, Bennett J, Dolin R. Mandell, Douglas and Bennett's Principles and Practice of Infectious Disease.8th edition. Philadelphia. Elsevier Saunders 2015.

3. World Health Organization (WHO),. WHO position paper on diphtheria.Wkly Epidemiol Rec. 2006;81(3):21-32.PMID: 16671238

4. Zakikhany K, Efstratiou A. Diphtheria in Europe: current problems and new challenges.Future Microbiol. 2012;7(5):595607. DOI: 10.2217/fmb.12.24 PMID: 22568715

5. European Centre for Disease Prevention and Control (ECDC). Cutaneous diphtheria among recently arrived refugees and asylum seekers in the EU, 30 July 2015. Stockholm: ECDC;2015. Available from: http://ecdc.europa.eu/en/publications/ Publications/Diphtheria-cutaneous-EU-July-2015.pdf

6. Catchpole M, Coulombier D. Refugee crisis demands European Union-wide surveillance!Euro Surveill. 2015;20(45). DOI: 10.2807/1560,7917.ES.2015.20.45.30063 PMID: 26606945

7. Finnish National Institute for Health and Welfare (THL). Aiemmat rokotuskattavuustutkimukset. [National immunization coverage estimates]. Helsinki: THL. [Accessed 14 Dec 2015]. Finnish. Available from: https://www.thl.fi/fi/web/ rokottaminen/kansallinen-rokotusohjelma/rokotuskattavuus/ aiemmat-rokotuskattavuustutkimukset

8. European Centre for Disease Prevention and Control (ECDC). A case of diphtheria in Spain, 15 June 2015. Stockholm: ECDC;
2015. Available from: http://ecdc.europa.eu/en/publications/ Publications/diphtheria-spain-rapid-risk-assessmentjune-2015.pdf

License and copyright

This is an open-access article distributed under the terms of the Creative Commons Attribution (CC BY 4.0) Licence. You may share and adapt the material, but must give appropriate credit to the source, provide a link to the licence, and indicate if changes were made.

This article is copyright of the authors, 2016. 